\title{
Las obras de urbanización y el deber de su conservación en la Ley $7 / 2002$, de Ordenación Urbanística de Andalucía
}

\author{
José A. López Pellicer \\ Profesor Titular de Derecho Administrativo \\ Universidad de Murcia
}

\begin{abstract}
SUMARIO: I. INTRODUCCIÓN. II. LAS OBRAS DE URBANIZACIÓN. 1. Concepto y naturaleza. 2. Obras de urbanización y obras ordinarias: supuestos y régimen. III. EJECUCIÓN DE LAS OBRAS DE URBANIZACIÓN. 1. Presupuestos. 2. Actuación pública y actuación privada en la ejecución de las obras de urbanización: sistemas de actuación y formas de gestión. IV. LA EJECUCIÓN MATERIAL DE LAS OBRAS DE URBANIZACIÓN. 1. Sobre el proyecto de urbanización a ejecutar. 2. Ocupación de los terrenos en los que hayan de realizarse las obras de urbanización. 3. Control administrativo de la ejecución de las obras de urbanización. 4. Recepción de las obras de urbanización. V. CONSERVACIÓN DE LAS OBRAS DE URBANIZACIÓN. 1. Atribución legal al municipio del deber de conservación. 2. Conservación a cargo de los propietarios agrupados en una entidad urbanística de conservación. 3. La conservación de las urbanizaciones preexistentes en el régimen transitorio de la Ley andaluza.
\end{abstract}

\section{INTRODUCGIÓN}

La realización de obras de urbanización forma parte normalmente, en el estado actual de nuestro ordenamiento urbanístico (autonómico), como uno de los elementos -básicamente, material y técnico-, de la actividad de ejecución de los planes de urbanismo, que legalmente viene configurada desde la precedente legislación estatal en esta materia, como una competencia propia de la Administración pública (local, básicamente). La actividad de ejecución de los planes urbanísticos, y dentro de ella, de obras de urbanización, es, pues, así, una actividad administrativa, en cuanto atribuida legalmente a la competencia de aquélla, si bien se admite la actuación de los particulares en determinados supuestos de autogestión, entre los que destaca de forma prototípica el de actuación por el denominado sistema de compensación, que las leyes autonómicas por lo general mantienen. La actividad particular de ejecución de 
obras urbanizadoras no se reduce, sin embargo, a este supuesto; también se produce en otros en los que se instrumenta la actuación administrativa mediante fórmulas de gestión indirecta, contractual o convenida, cuando la Administración asume el protagonismo de la ejecución y, en ésta, de la urbanización, que realiza mediante sistemas de actuación pública, lo que sucede tradicionalmente en el denominado sistema de cooperación y en el de expropiación forzosa, cuando se utiliza la técnica de la concesión para realizar la obra urbanizadora del ámbito de actuación, llámese éste polígono, unidad de actuación o de ejecución.

Esto es debido fundamentalmente a que la facultad o derecho de urbanizar se configura desvinculado del derecho de propiedad del suelo, al admitirse la posibilidad de entrar en juego personas o entidades particulares no propietarias a las que la Administración titular de la competencia pública en la materia adjudique, mediante concurso público de proyectos en competencia, la condición de urbanizador. El supuesto, tradicionalmente constituido por la llamada concesión urbanística, ofrece además otras posibilidades alternativas a este mecanismo proveniente de la legislación urbanística estatal, como el que ha introducido la innovadora Ley valenciana 6/1994. El supuesto de urbanizador no propietario ha tenido explícito reflejo en la Ley estatal 6/1998, de 13 de abril, en su artículo 4.3, al referirse a los supuestos de actuación pública mediante la promoción de la iniciativa privada "aunque ésta no ostente la propiedad del suelo" ${ }^{\text {. }}$

Pues bien, a las cuestiones que suscita la realización de las obras de urbanización dentro de la más amplia y compleja temática de la ejecución del planeamiento urbanístico y, por ello, bajo los presupuestos y exigencias jurídicas que supone aplicar los correspondientes sistemas de actuación, en la Ley andaluza 7/2002, de 17 de diciembre (LOUA), no como tales sino concretamente desde la perspectiva de la ejecución de este tipo de obras, en los diversos supuestos de actuación pública y de actuación privada; así como de su conservación, una vez ejecutadas y recibidas por la Administración, se refieren las consideraciones que a continuación se hacen.

${ }^{1}$ T.R. FERNÁNDEZ RODRÍGUEZ: Manual de Derecho Urbanistico, El Consultor, 16 edición, 2001, pág. 184 y sgs. Asimismo y a propósito de la famosa sentencia del Tribunal de Justicia de la CEE de 12 de julio de 2001, R. GÓMEZ-FERRER MORANT: "Gestión del planeamiento y contratos administrativos”, en esta misma Revista Andaluza de Administración Pública, no 46 (2002), pág. 11 y sgs., y en especial, respecto a la gestión indirecta por medio de agente urbanizador, págs. 43 a 55. Asimismo, véanse las interesantes consideraciones que, a propósito de la incidencia en esta materia, del régimen de contratación administrativa, hacen asimismo T.R. FERNÁNDEZ, L. PAREJO, F. BLANC CLAVERO y A. DE ASÍS ROIG, sobre todo, en Documentación Administrativa, no 261-262 (2002), monográfico sobre urbanismo y contratación administrativa. 


\section{LAS OBRAS DE URBANIZACIÓN}

\section{Concepto y naturaleza}

Las obras de urbanización constituyen una actividad material que, en ejecución del planeamiento urbanístico en un determinado ámbito de gestión que la citada Ley andaluza denomina unidad de ejecución-, consiste en realizar la transformación del suelo urbano o urbanizable en urbanizado, mediante la ejecución de una serie de infraestructuras, construcciones e instalaciones (vialidad, redes de saneamiento y abastecimiento de agua, suministro de energía eléctrica, ajardinamiento, etc), que han de sufragar los propietarios en la medida en que estas obras sirvan al propio ámbito de actuación.

En cuanto actividad material de transformación del suelo, en que este tipo de obras consiste y cuyo resultado tangible se incorpora a los terrenos donde se ejecutan, es indudable que las obras de urbanización tienen carácter inmobiliario, y que dada su finalidad pública, en razón de su destino para el uso público -viario, jardines- o el servicio público - saneamiento, agua potable, telefonía, etc.- también tienen una vocación demanial, ya que una vez ejecutadas se incorporan normalmente al dominio público (si exceptuamos la instalación de servicios liberalizados, si bien de interés general, como las telecomunicaciones y la energía eléctrica).

La Ley estatal 6/1998 establece el deber a cargo de los propietarios de suelo urbano y del suelo urbanizable, de costear la urbanización y, en su caso, ejecutarla ${ }^{2}$, en suma financiarla, excepto como es lógico en caso de expropiación forzosa, aunque la ejecución de las obras depende del "sistema de actuación" que determine la Administración: sólo en el sistema de compensación los propietarios vienen facultados de suyo, en virtud del propio sistema, a asumir la actuación urbanizadora del ámbito de gestión, ya que en los demás sistemas, de actuación pública, sólo vendrán facultados para hacerlo en caso de que la Administración municipal les otorgue esta posibilidad de forma convenida o contractual, mediante concesión o atribución de la condición de agente urbanizador, en competencia incluso con terceros no propietarios.

Ni que decir tiene que, en razón de la titularidad pública de este tipo de obras y de su finalidad para el uso o el servicio público (matizada respecto a los indicados servicios de interés general), según el tipo de infraestructura, se

\footnotetext{
${ }^{2}$ Artículos 13 y 14.1 y 2 , e) en suelo urbano, y 15.1 y 18.6 en suelo urbanizable.
} 
infiere que se está en presencia de una obra pública, si bien haya de precisarse esta afirmación puntualizando lo que, atendiendo a las peculiaridades del ordenamiento urbanístico, a continuación se indica:

- Que la financiación de esta clase de obras se efectúa, por lo general, no por la Administración sino por los propietarios de suelo, en cumplimiento éstos de un deber legal, de una carga que la Ley les impone a modo de compensación a la Administración, en definitiva a la comunidad social cuyos intereses ésta gestiona, y cuya justificación material se halla en los aumentos de valor que para aquéllos genera la acción urbanística pública ${ }^{3}$. El supuesto -y el efecto- es pues equivalente en los sistemas de actuación en los que se mantiene la propiedad del suelo, cooperación y compensación, a como si los propietarios satisfaciesen a la Administración un impuesto que gravase el incremento de valor experimentado por la propiedad del suelo por efecto de la acción administrativa de planificación y de gestión urbanística.

El artículo 103 de la Ley andaluza 7/2002 relaciona los "gastos de urbanización" que corresponden a la propiedad del suelo en una unidad de ejecución, e incluyen el coste de las obras de urbanización, así como otros conceptos de gasto que cabe denominar de gestión de la ejecución del plan -por la redacción del proyecto urbanización, gastos de tramitación, gestión del sistema de actuación, etc.-, cuyo reparto entre todos los propietarios ha de hacerse justamente mediante reparcelación ${ }^{4}$, mediante la asignación de las correspondientes cuotas de urbanización, que con carácter real recaen como gravamen sobre las parcelas adjudicadas.

En suma, pues, el pago de las obras de urbanización, aunque públicas, no corre a cargo de la Administración, sino de los propietarios de suelo, que vienen obligados a ello legalmente, en cumplimiento de un deber público, que la Ley les impone. ¿Desvirtúa esta particularidad el carácter público de las obras de urbanización?. No nos lo parece, por lo mismo que tampoco desvirtúa la naturaleza de un servicio público el que, incluso en caso de concesión, el mismo se financie mediante tarifas que han de abonar los particulares usuarios.

- De otra parte, también ha de tenerse en cuenta que la adjudicación de las obras de urbanización, en cuanto públicas, viene sujeta en principio a la le-

${ }^{3}$ Artículo 47, pfo. 2 de la Constitución, en conexión con el artículo 3 de la citada Ley 6/1998, y en Andalucía asimismo el artículo 3.1, g) y el 49.2 de la Ley 7/2002.

${ }^{4}$ Artículo 100.2, b) de la Ley 7/2002, de Ordenación Urbanística de Andalucía. 
gislación de contratos de las Administraciones públicas, es decir, al Real Decreto Legislativo 2/2000, de 16 de junio, en atención no sólo de la Administración o entidad que las adjudica (artículo 1) sino también atendiendo a su objeto (artículo 120), en conexión con la normativa de régimen local (artículos 88 y 89 del Real Decreto legislativo 781/1986, de 18 de abril), aunque con las particularidades propias del ordenamiento urbanístico, a las que no parecen adecuarse -ni ser por ende aplicables- los procedimientos de adjudicación, pero sí cumplirse los principios y normas de publicidad y concurrencia en el ámbito comunitario europeo siempre que, por su cuantía económica, las obras -públicas- de urbanización vengan incluidas en el umbral fijado por la Directiva CEE 93/37, de 14 de junio de 1993, del Consejo, tal como ha considerado con detalle, en el número 46 de esta misma Revista andaluza, R. GÓMEZ-FERRER MORANT ${ }^{5}$.

- También ha de tenerse en cuenta respecto a determinadas instalaciones como las relativas a la electrificación, telecomunicaciones y telefonía, cuyos servicios han sido objeto de liberalización, que la ejecución de las redes de distribución y conexión a las generales han de ser costeadas por los propietarios de suelo, pero sin perjuicio de que éstos puedan resarcirse de los gastos efectuados con cargo a las entidades o compañías prestadoras de dichos servicios ${ }^{6}$. La liberalización de estos servicios en un mercado abierto y competitivo, como es el comunitario europeo, ha determinado un importante cambio no sólo del régimen jurídico de este tipo de servicios, antes publificados, y en consecuencia de los bienes a ellos destinados, que dejan de tener por ende estricto carácter demanial, si bien mantienen su afectación a un destino público, de interés general, que asimismo justifica y determina su protección ${ }^{7}$. No desvirtúa

\footnotetext{
5 Antes citado (en la nota 1). Vid., asimismo, la opinión de A. DE ASÍS ROIG, en "Caracterización de la función de urbanización”, en Doc. Administrativa, cit. pág. 226 y s.; y la de A. MORENO MOLINA, allí citada.

${ }^{6}$ Véase el estudio de J. M. SALA ARQUER, "El promotor inmobiliario ante los nuevos servicios liberalizados”, en la Rev. Urbanismo y Edificación, de Aranzadi, no 2, 2000, pág. 35 y sgs.

${ }^{7}$ Se trata de bienes privados afectados a un destino público. Se rompe la ecuación fines públicos_dominio público, fines privados_bienes patrimoniales, incluso en manos de particulares. El dominio público queda ampliamente rebasado como técnica de aseguramiento del destino público de los fines (J. I. MORILLO-VELARDE: "El estatuto jurídico de los bienes. Las transformaciones del Derecho Público de bienes: del dominio público a las cosas públicas", pág. 35 y sgs.). Sobre las redes de servicios en el ámbito local, I. GONZÁLEZ RÍOS: El dominio público municipal: régimen de utilización por los particulares y compañias prestadoras de servicios, Edit. Comares, Granada, 2001, esp. pág. 93 y sgs.
} 
sin embargo esto, a nuestro modo de ver, la naturaleza pública que globalmente, en su conjunto y a los efectos indicados, las obras de urbanización tienen, en razón de la finalidad en todo caso pública de las mismas y la especial protección pública de los bienes integrantes de las correspondientes redes de servicios, sean éstos públicos o de interés general, proyectados y a instalar conforme al correspondiente proyecto o proyectos de urbanización y cuyo objeto es en definitiva realizar la función pública de ejecución material del planeamiento urbanístico ${ }^{8}$.

\section{Obras de urbanización y obras ordinarias: supuestos y régimen}

Las obras de urbanización, que se rigen por la legislación urbanística, implican en su ejecución la aplicación conjunta de dos técnicas: una, la fijación del ámbito espacial que constituye lo que se denomina unidad de ejecución, cuya delimitación ha de hacerse de modo que haga posible no sólo la viabilidad técnica y económica de la actuación urbanística, sino también la distribución de beneficios y cargas de la ordenación y gestión urbanística ${ }^{9}$; o otra, el proyecto de urbanización, que es un tipo de proyecto técnico de obras que tiene por objeto "llevar a la práctica", esto es, ejecutar técnica y materialmente, el plan urbanístico previo, mediante el desarrollo global y completo de las determinaciones que este plan prevé, como determina la Ley andaluza 7/2002 en su artículo 98, respecto a las "obras de vialidad, saneamiento, instalación y funcionamiento de los servicios públicos y de ajardinamiento, arbolado y amueblamiento de parques y jardines", que relaciona el artículo 113 de la Ley, así como otras que vengan "previstas por los instrumentos de planeamiento", las cuales pueden ampliar así las obras que la Ley determina a propósito de fijar la carga que en definitiva constituyen los costes de urbanización.

A las obras de urbanización así definidas, siguiendo una línea ya trazada desde la precedente legislación urbanística estatal ${ }^{10}$, se contraponen, diferen-

\footnotetext{
${ }^{8}$ Art. 98.1, en conexión con el 113.1, ambos de la Ley andaluza 7/2002. Asimismo, de modo general, el artículo 220.1 de la Ley (estatal) 13/2003, de 23 de mayo, de concesión de obras públicas, que incluye en su finalidad las actividades o servicios económicos de interés general.

${ }^{9}$ Art. 105.1 de la Ley andaluza 7/2002.

${ }^{10}$ Artículo 11 de la Ley del Suelo de 12 de mayo de 1956; 15 de la Ley del Suelo de 1976, Texto Refundido de 9 de abril; y 92 del Texto Refundido de 26 de junio de 1992 . El artículo 89 del Texto Refundido de Régimen Local de 18 de abril de 1986 establecía, y establece, que las obras de urbanización "se rigen por la legislación urbanística", diferenciándolas así de las "obras ordinarias".
} 
ciandolas por su régimen y según la normativa de régimen local -citada en la nota precedente-, las llamadas "obras ordinarias". A sensu contrario de las anteriores, éstas son las que se proyectan y ejecutan de forma aislada, no integrada en el ámbito global de una unidad de ejecución: el artículo 67.3 del Reglamento estatal de Planeamiento Urbanístico de 1978 se refería a los proyectos de obras ordinarias como los que "no tengan por objeto desarrollar integralmente el conjunto de determinaciones de un plan de ordenación": delimitación negativa que asimismo utiliza la Ley andaluza 7/2002, en su artículo 143.1, para calificar a las obras ordinarias como tipo de obras públicas en el caso de que "no esté prevista en el planeamiento urbanístico, ni se efectúe por el municipio delimitación de unidad de ejecución", en cuyo supuesto -añadela ejecución "se llevará a cabo mediante obras públicas ordinarias, de acuerdo con la legislación que sea aplicable por razón de la Administración pública actuante", sea ésta por tanto la local, la autonómica o la estatal, según quién sea la que ostente la titularidad de la competencia en la materia a que el tipo de obra se refiera ${ }^{11}$.

La imprecisión que supone no obstante calificar así, de manera negativa, este tipo de obras públicas, como ordinarias, diciendo genéricamente que son "actuaciones urbanizadoras no integradas", no es óbice para entender, resaltando su significación en sentido positivo, que se trata de obras relativas a actuaciones aisladas que, aun cuando se proyecten y ejecuten al margen de las actuaciones sistemáticas en unidades de ejecución, también pueden realizarse, como dice el citado precepto legal, para " la ejecución del planeamiento, salvo la edificación”, a los efectos especialmente de la obtención del suelo necesario para las dotaciones públicas por alguno de los mecanismos que determina el mismo artículo 143, en su apartado 2. Supuesto éste de obras ordinarias que no excluye, por otra parte y a nuestro juicio, concretamente en el ámbito municipal, la posibilidad de obras ordinarias conforme a la normativa de régimen local a que antes se ha hecho mención. Cabe distinguir según esto, varios tipos de obras públicas a este respecto:

1) Obras de urbanización que, en ejecución del planeamiento urbanístico, se realicen en el ámbito de una unidad de ejecución y conforme al sistemas de actuación y forma de gestión previamente fijados. Estas son las actuaciones urbanizadoras prototípicas, a que se refieren y sirven de base técnica-

${ }^{11}$ La Ley andaluza se refiere asimismo a la forma de obtención del suelo en que las obras ordinarias hayan de realizarse, en el artículo 143.2, y respecto a las dotaciones el artículo 139.2, b. Asimismo, se refiere a las "obras públicas ordinarias", que distingue de las "obras de urbanización", el artículo 86, d, dentro de la "actividad administrativa de ejecución". 
mente los proyectos de urbanización del artículo 98 de la Ley andaluza $7 / 2002$.

2) Obras de urbanización proyectadas y realizadas para la ejecución de dotaciones públicas, sean estas dotaciones locales o supralocales o generales, autonómicas o estatales, pero realizadas asimismo en cualquier caso en ejecución del planeamiento urbanístico. A este grupo o tipo de obras se refiere asimismo la LOUA calificándolas como "actuaciones urbanizadoras", aunque a diferencia de los anteriores "no integradas", por lo que se las califica legalmente como "obras públicas ordinarias". A este tipo se refiere la Ley en sus artículos 139.2, b, y 143.1, a los indicados efectos y específicamente para legitimar la obtención del suelo necesario para ejecutar dotaciones públicas; y sin perjuicio de aplicar la normativa que corresponda según la Administración actuante.

3) Un último grupo es el que viene constituido, concretamente en el ámbito local, por las tradicionales obras municipales ordinarias, que asimismo los entes locales realizan conforme a la normativa de régimen local contenida en el citado Texto refundido de 18 de abril de 1986, en sus artículos 88 a 94 .

A diferencia de la financiación de las obras de urbanización del primer grupo, a cargo de los propietarios de la correspondiente unidad de ejecución, según lo dicho, mediante la imposición de las correspondientes cuotas de urbanización a aquéllos, en el caso de las obras públicas ordinarias, incluidos en los otros dos grupos, su costeamiento por la Administración actuante incluye la posibilidad de imponer contribuciones especiales, conforme a la normativa tributaria correspondiente, según es tradicional a este respecto en nuestro ordenamiento jurídico.

\section{EJECUCIÓN DE LAS OBRAS DE URBANIZACIÓN}

\section{Presupuestos}

La realización en suelo urbano o urbanizable de actividad urbanizadora, en los dos primeros supuestos antes indicados, presupone la existencia de un planeamiento urbanístico detallado (artículo 96.1 LOUA), aunque sólo en el primero de ellos supone propiamente la ejecución de obras de urbanización sensu estricto, en cuanto obras realizadas de forma integrada y sistemática en el ámbito de una unidad de ejecución, previamente delimitada por el planeamiento que se ejecute o bien por la Administración municipal conforme a lo que establece el artículo 106 de la misma Ley. Aun cuando, según lo dicho, se califique como "actividad urbanizadora", pero "no integrada", el supuesto de 
"obras públicas ordinarias", a los efectos de obtener del suelo preciso para realizar dotaciones públicas, la exposición que sigue se va a centrar fundamentalmente en el régimen de la actividad -obra- urbanizadora "integrada" en el ámbito de unidades de ejecución y conforme a los sistemas de actuación que la propia Ley regula; ya que en los demás supuestos y con la salvedad indicada, la ejecución de las obras responde a las técnicas propias de las tradicionales obras públicas ordinarias (contratación, financiación).

Los presupuestos de la actividad -urbanizadora- de ejecución han de completarse con otras dos exigencias, o requisitos previos, que asimismo definen la ejecución de las obras de urbanización propiamente dichas y que se refieren: una, al cuándo, o plazos en que las obras han de realizarse ${ }^{12}$; y otra exigencia, básica $^{13}$, según la cual antes de proceder a la ejecución material de las obras, en ejecución del planeamiento, ha de resolverse el problema jurídico de llevar a cabo el reparto justo de beneficios y cargas urbanísticas mediante la aprobación del proyecto de reparcelación ${ }^{14}$, exigible en principio en cualquier sistema de actuación y no sólo, como sucedía en la legislación precedente, en el de cooperación ${ }^{15}$.

Bajo estos presupuestos legales, procede determinar quien o quienes son los sujetos, públicos o privados, legitimados para llevar a cabo las obras de urbanización, y la forma de instrumentar su ejecución.

\section{Actuación pública y actuación privada en la ejecución de las obras de urba- nización: sistemas de actuación y formas de gestión}

De los sistemas de actuación que la LOU regula, el de compensación se configura como de "actuación privada", y los de cooperación y expropiación como de "actuación pública"16. La aplicación del sistema de compensación su-

${ }^{12}$ Artículos 18.2, b; 86, b; y 88 de la LOUA.

13 Que establece la Ley estatal 6/1998, de 13 de abril, en sus artículos 14.2, d (para el suelo urbano no consolidado) y 18.5 (respecto del suelo urbanizable).

${ }^{14}$ Artículos 100 a 104 de la LOUA.

15 Así, en el sistema de expropiación, el supuesto del artículo 114.3 de la LOUA; en el de cooperación, artículos 123.3 y 127.1; y en el de compensación, artículos 135 y 136 . Véase a este respecto, el estudio de F. LÓPEZ MENUDO: "Comentarios al proyecto de LOU de Andalucía”, en Rev. de Urbanismo y Edificación, Edit. Aranzadi, nº 6 (2002), pág. 37 y s.

${ }^{16}$ Artículo 107.1. 
pone de suyo una forma de gestión indirecta, por particulares, que puede ser el propietario o propietarios que cuando menos ostente/n más del 50 por 100 de la superficie de la unidad de ejecución, o bien cualquier persona, aunque no sea propietaria de suelo en ésta, pero que esté interesada en realizar la actividad urbanizadora como "agente urbanizador". En los sistemas de actuación pública, tanto en el de cooperación como en el de expropiación, la gestión de las obras puede ser directa o indirecta, es decir por la propia Administración, sin perjuicio de que conforme a la legislación administrativa de contratos ésta haya de seleccionar a un contratista o concesionario para llevar a cabo la ejecución de las obras de urbanización.

Así pues, de la combinación de sistemas de actuación y formas de gestión resultan varios supuestos, que inicialmente pueden darse para llevar a cabo la ejecución de las obras:

A) Ejecución por contratista seleccionado mediante el procedimiento previsto en la legislación de contratos de las Administraciones públicas

Se da este supuesto en caso de que la Administración actuante, en el sistema de cooperación, opte conforme al artículo 123.1, B, a, LOUA, por esta modalidad de ejecución, que define este supuesto como de "gestión directa". La aplicación de la Ley de Contratos, texto refundido aprobado por el Real Decreto legislativo 2/2000, de 16 de junio, que regula el contrato de obras públicas, determina en consecuencia que el adjudicatario del contrato haya de seleccionarse mediante procedimiento licitatorio -subasta o concurso-, libre o restringido según proceda, y sólo excepcionalmente mediante procedimiento negociado ${ }^{17}$.

La misma forma de llevar a cabo la ejecución de las obras ha de aplicarse en el caso de que la actuación urbanística se realice por el sistema de expropiación mediante gestión directa ${ }^{18}$.

En el supuesto de "actuación privada", mediante el sistema de compensación, si fueren los propietarios de suelo de la unidad de ejecución los encargados de la actividad urbanizadora, la Junta de compensación que se consti-

17 Artículos 74 a 93 y 120 a 141 TRLCAP cit., con las particularidades que respecto al proyecto de urbanización establece la LOUA (art. 98 y 99) y su financiación (arts. 123.2 y 124).

18 Artículo 116, a, LOUA. 
tuya -y que tiene legalmente naturaleza administrativa- es la que gestiona y "asume la directa responsabilidad de la ejecución de las obras de urbanización", entre otras funciones, sin perjuicio de que para adjudicarlas haya de cumplir, conforme a la citada Directiva comunitaria europea 93/37 -interpretada por la sentencia del Tribunal de Justicia CE de 12 de julio de 2001-, que traspone la citada legislación administrativa de contratos, las prescripciones del citado Texto refundido relativas a la publicidad, procedimientos de licitación y formas de adjudicación del contrato ${ }^{19}$. Parece que, no obstante, habría de exceptuarse del supuesto el caso de propietario único y el de que en el procedimiento que la Ley andaluza regula para establecer el sistema de compensación en su artículo 131, la Administración acuerde la aprobación de alternativa presentada por agente urbanizador, cuando éste sea una empresa urbanizadora que haya presentado el proyecto de urbanización, habida cuenta del carácter concurrencial que el procedimiento administrativo de adjudicación tiene; aunque para no soslayar la exigencia de publicidad comunitaria, cuando ésta exigencia proceda según la Directiva 93/37, habría de articularse de alguna forma en la fase de información pública, para que la concurrencia, con la posible presentación de alternativas, por empresa urbanizadora, alcance al ámbito comunitario europeo.

\section{B) Ejecución de las obras de urbanización mediante concesión administrativa}

La actuación pública mediante el sistema de cooperación, como también en el de expropiación, puede instrumentarse mediante gestión indirecta, que pueda adoptar, en cualquiera de ellos, la modalidad de concesión administrativa de la actividad de ejecución de obras públicas de urbanización con arreglo a las normas que la Ley andaluza 7/2002 establece y que modulan por razón de la materia las generales de la citada legislación de contratos de las Administraciones públicas $^{20}$.

Caracteriza esencialmente a la concesión de obras de urbanización, tradicionalmente conocida como concesión urbanística ${ }^{21}$, que el adjudicatario

\footnotetext{
${ }^{19}$ Véase el estudio efectuado por R. GÓMEZ-FERRER MORANT cit. en la nota 1, y publicado en el nº 46 de esta Revista, pág. 34 a 41, a que remitimos en este punto.

${ }^{20}$ Arts. 220 y sgs., según la regulación establecida por la Ley -estatal- 13/2003, de 23 de mayo, reguladora del contrato de concesión de obras públicas.

${ }^{21}$ Remito a la exposición hecha en La concesión administrativa en la esfera local, IEAL, 1975, pág. 227 y sgs.
} 
de este tipo de obra pública se resarce del coste de la ejecución mediante su explotación económica, que supone la enajenación o venta de los terrenos urbanizados y edificables -solares- o de las edificaciones, viviendas, etc, realizadas asimismo, cuando estas obras vengan también comprendidas en la actividad administrativa de ejecución.

En este tipo de concesión administrativa, no se otorgan al concesionario facultades para la explotación de servicios públicos, sino sólo la actividad administrativa de ejecución consistente en realizar las obras de urbanización y -en su caso- de edificación en el seno de la correspondiente unidad de ejecución ${ }^{22}$. Lo que diferencia a esta modalidad de concesión de obra pública de la de servicio público, e incluso de la concesión de obra pública regulada de modo general en la Ley de Contratos antes citada, que puede incluir en su objeto asimismo la prestación de servicios públicos. Se está ante un supuesto peculiar de concesión que no encaja estrictamente en el concepto legal del artículo 220 -antes 130- de la Ley de Contratos, ya que la contraprestación al concesionario no consiste en el hecho de explotar una obra o en este derecho acompañado del de percibir un precio ${ }^{23}$, sino en el derecho de enajenar o vender el concesionario las parcelas urbanizadas.

Ahora bien, en la Ley andaluza que consideramos, cabe distinguir varios supuestos de concesión de obras de urbanización y, eventualmente, de edificación, a saber:

a) El tradicional supuesto de concesión urbanística vinculado al sistema de expropiación, en el cual el concesionario asume la condición de beneficiario de la expropiación, que habrá de abonar el justiprecio de las fincas y derechos a expropiar en la unidad de ejecución (excepto como es lógico a los propietarios liberados: artículo 121 de la Ley).

Regulado este supuesto en la precedente legislación urbanística estatal ${ }^{24}$, la Ley andaluza 7/2002 viene a asumirlo también ahora, como modalidad de

${ }^{22}$ Art. 86, d) LOUA, en conexión con el 116, b) de la misma Ley (en el sistema de expropiación) y el 123.1, B, b) (en el sistema de cooperación).

${ }^{23}$ En este sentido, GÓMEZ-FERRER MORANT, cit. en la nota 1, pág. 41.

${ }^{24}$ Art. 133.2 de la Ley del Suelo de 12 de mayo de 1956; artículo 114.2 de la Ley del Suelo (Texto Refundido, aprobado por R. D. Legislativo 1356/1976), de 9 de abril de 1976, y arts. 211 y 212 de su Reglamento de Gestión Urbanística, de 25 de agosto de 1978; y finalmente, el artículo 172 de la Ley del Suelo (Texto Refundido, aprobado por R. D. Legislativo 1/1992), de 26 de junio de 1992, en conexión con los supuestos del precedente Reglamento de Gestión. 
gestión indirecta que es, en su artículo 116, b, si bien ampliándolo con la posibilidad de que la iniciativa proceda de "agente urbanizador", con determinadas particularidades procedimentales relativas a la propia iniciativa (artículo 117) o a la concesión a iniciativa de la Administración actuante (artículo 118), con adjudicación final de la concesión, sea cual sea la forma de la iniciativa, a la mejor alternativa u oferta, con formalización final mediante convenio urbanístico (artículo 119).

Asimismo, se admite legalmente la posibilidad de otorgamiento de la concesión administrativa a varios licitadores "conjuntamente", siempre que exista previo acuerdo entre ellos y la Administración admita -acepte, dice la Ley- el contenido de este acuerdo ${ }^{25}$.

b) La concesión de obras de urbanización en el sistema de cooperación

En este supuesto, la concesión, en la actividad administrativa de ejecución, de obras de urbanización y en su caso de edificación, en el ámbito de una unidad de ejecución, viene asimismo contemplada en la Ley 7/2002 (artículo 123.1. B, b, en conexión con el 86, d). En este supuesto, la concesión ha de instrumentarse mediante concurso que ha de convocar, tramitar y resolver la Administración actuante, tratándose como se trata de un sistema de actuación pública.

En este caso, que presupone la disociación del derecho de propiedad del suelo y del derecho urbanizar, los propietarios pueden no obstante competir, en régimen de concurrencia, por la concesión de la urbanización, aun cuando tienen legalmente un derecho de preferencia sobre cualquier otra oferta equivalente formulada por un tercero no propietario ${ }^{26}$.

C) Ejecución de obras de urbanización mediante sociedad de capital público, integro o mixto

A los efectos de la gestión de obras de urbanización en cualquiera de los sistemas de gestión pública -cooperación o expropiación-, ha de tenerse en cuenta que en el supuesto de que la Administración actuante haya constituido y actúe mediante una sociedad de capital íntegramente público, la gestión de

\footnotetext{
${ }^{25}$ Art. 119.1, 2ª , LOUA.

${ }^{26}$ Art. 50, D, a, LOUA. Asimismo, específicamente respecto al sistema de expropiación, el artículo 118, c, de la propia Ley.
} 
la actividad urbanizadora ha de considerarse como modalidad de gestión pública directa, conforme a la Ley andaluza 7/2002 (artículo 90,2, b); en cambio, será indirecta la gestión en caso de actuar la Administración de forma instrumental, por sociedad de capital mixto ${ }^{27}$, en la cual aquélla tenga una participación mayoritaria del capital o, en todo caso, si ejerciere el control efectivo o tuviese la posición decisiva en el funcionamiento de la sociedad (artículo 90.3, b, LOUA).

D) Ejecución de forma consorcial de obras de infraestructura, equipamientos y dotaciones públicas urbanisticas

La LOUA prevé y regula asimismo -en sus artículos 144 a 147- la ejecución de obras de esta naturaleza de modo conjunto por la Administración de la Junta de Andalucía, los municipios y, en su caso, otras Administraciones públicas, a cuyo objeto prevé la posibilidad de constituir una organización común, en forma de consorcio, a constituir voluntariamente por todas ellas, para actuar en "áreas de gestión integrada", de manera que la ejecución y gestión mediante este tipo de organización asegure la "coordinación e integración" de las actuaciones de todas ellas conjuntamente.

El consorcio implica, como es sabido, la constitución de una entidad administrativa, a la cual se atribuye o encomienda la gestión de determinados servicios o actividades, en nuestro caso la ejecución de obras y equipamientos urbanísticos, a realizar por sustitución de las Administraciones consorciadas. Puede abordarse así, de este modo, la gestión unitaria de competencias dispersas, pertenecientes a cada una de las Administraciones integradas en el consorcio. De aquí que la Ley 30/92 requiere básicamente que en los órganos de decisión de éste, han de estar integradas "todas las entidades consorciadas, en la proporción que se fije en los estatutos respectivos", esto es, que las propias entidades integrantes del consorcio tienen la disposición sobre la actividad de éste, con carácter puramente instrumental, para el ejercicio en común de las propias competencias.

27 Artículo 90.3, b, de la LOUA. En los contratos que la sociedad celebre con terceros y que tengan por objeto la ejecución de las obras, habrá que observar los principios de publicidad y conservancia: así, R. GÓMEZ-FERRER MORANT, cit. en la nota 1, pág. 42; y M. LORA-TAMAYO VALLVÉ: "Ejecución de obra urbanizadora y Derecho comunitario", RAP no 159 (2002), pág.269, lugares donde se cita el RD 1169/1978, de 2 de mayo, de constitución de sociedades urbanísticas (en esp., art. 3.5). Véase asimismo, de modo más general, el estudio de M. REBOLLO PUIG: "Los entes institucionales de la Junta de Andalucía y su utilización como medio propio", RAP nº 161 (2003), pág. 359 y sgs. 


\section{LA EJECUCIÓN MATERIAL DE LAS OBRAS DE URBANIZA- CIÓN}

La realización de las obras urbanizadoras, en ejecución del planeamiento urbanístico y en el ámbito de una unidad o área de ejecución, no sólo presupone como se ha indicado la previa delimitación de ésta y del correspondiente proyecto de equidistribución, o reparcelación, de beneficios y cargas, aplicable según la LOUA en cualquier sistema y no sólo en el de cooperación. La actividad de ejecución incluye, además de éstas operaciones o actuaciones digamos jurídicas, otras en las que sustancialmente consiste y que tienen por objeto llevar a cabo la transformación material de la realidad física con la realización de las obras de vialidad, saneamiento, abastecimiento de agua, energía eléctrica, etc, que integran técnicamente el proyecto o proyectos de urbanización a ejecutar (1), en unos determinados terrenos que será necesario por ello ocupar (2) y que, una vez realizadas debidamente bajo el control de la Administración (3), han de ser objeto de recepción por ésta (4).

\section{Sobre el proyecto de urbanización a ejecutar}

Las obras presuponen, pues, técnicamente la existencia de un tipo de proyecto, el proyecto de urbanización, aprobado por la Administración muni$\mathrm{cipal}^{28}$. En el sistema de expropiación y en el de cooperación, la elaboración del proyecto se efectuará por la propia Administración actuante, a no ser que ésta haya optado por la gestión indirecta, en cuyo caso la adjudicación de la concesión, en el sistema de expropiación, determina el deber del concesionario de presentar el proyecto (artículo 119.2 de la Ley), lo mismo que análogamente en el sistema de cooperación. Ahora bien, en caso de actuación privada, por el sistema de compensación, la presentación y aprobación del proyecto de urbanización se vincula a la iniciativa y procedimiento de este sistema ${ }^{29}$.

\section{Ocupación de los terrenos en los que hayan de realizarse las obras de ur- banización}

En la lógica del esquema legal está asimismo la exigencia de que previamente a la ejecución material del planeamiento, y por ende antes de iniciar la

\footnotetext{
28 Artículos 98.1, in fine, y 99.1 LOUA. Excepcionalmente, cuando las obras de urbanización sean complementarias de las de edificación -en el supuesto del artículo 99.2, en relación con el 98.4-, su aprobación se efectuará al otorgar la correspondiente licencia.

${ }^{29}$ Arts. 130.3 y 131.3 , b, pfo. 2, LOUA.
} 
actividad urbanizadora, haya sido resuelta la equidistribución de beneficios y cargas urbanísticas, incluidas en éstas la cesión obligatoria y gratuita de los terrenos donde han de situarse las correspondientes obras. En principio al menos, de aplicarse debidamente el régimen legal, el problema ha de venir resuelto como consecuencia de la aprobación administrativa del proyecto de reparcelación en el sistema de cooperación e incluso en el de expropiación cuando se produzca el caso de liberación de ésta de determinados terrenos ${ }^{30}$; en cuyos supuestos la aprobación del proyecto por la Administración actuante determina ope legis el efecto de transmitir al municipio, en pleno dominio y libre de cargas, de todos los terrenos de cesión obligatoria y que comporta en nuestro caso su afectación a los usos previstos por el planeamiento urbanístico, conforme establece la Ley 7/2002, en su artículo 102.2, a). La Administración actuante tendrá, pues, la disponibilidad de los terrenos necesarios para ejecutar las obras, en donde ha de efectuarse, antes de la tramitación del expediente de contratación administrativa de las obras, el correspondiente replanteo, y después, pero antes del comienzo de ejecución de éstas, la comprobación del replanteo ${ }^{31}$.

En el supuesto de actuación urbanística privada, por el sistema de compensación, habrá que tener en cuenta lo que determina el Reglamento de Gestión Urbanística de 1978, en su artículo 179.2 -aplicable conforme a la Disposición Transitoria Octava de la LOUA-, y según cuyo precepto reglamentario la Junta de Compensación y la empresa que tenga a su cargo la ejecución de las obras de urbanización podrán ocupar a este fin los terrenos objeto de cesión (al municipio, por virtud de la aprobación definitiva del proyecto de compensación, aquí y ahora de reparcelación), hasta que, una vez finalizadas las obras, sean recibidas éstas por la Administración.

\section{Control administrativo de la ejecución de las obras de urbanización}

En los sistemas de actuación pública, cooperación o expropiación, la Administración actuante dispone de los poderes de vigilancia y control sobre el contratista o concesionario, para velar por la debida ejecución y cumplimiento del objeto del contrato, no sólo de conformidad a la legislación de contratación de las Administraciones públicas, sino también según establece la nor-

${ }^{30}$ Arts. 114.3, 12; 123.3 y 127.1 LOUA.

31 Art. 129.1 del RD Legislativo 2/2000, de 16 de junio, que aprueba el Texto Refundido de la Ley de Contratos de la Administraciones Públicas (en adelante TRLCAP), sobre el replanteo, y 142 del mismo texto legal sobre la comprobación del replanteo. 
mativa urbanística, que atribuye a la Administración actuante mediante cualquiera de dichos sistemas, potestades de dirección, inspección y control, incluso respecto a la actividad privada de ejecución que se desenvuelve por el sistema de compensación ${ }^{32}$.

En lo que se refiere a este último sistema de actuación, el citado Reglamento de Gestión Urbanística, aplicable según lo dicho transitoriamente en la Comunidad andaluza, establece en su artículo 175.3, que la Administración viene facultada para -dice- vigilar la ejecución de las obras e instalaciones; y si alguna obra o instalación, o parte de ella, no se ejecutare de conformidad con el proyecto -de urbanización-, la Administración podrá ordenar la demolición de la obra o el levantamiento de las instalaciones y la nueva ejecución con cargo a la Junta de Compensación, quien a su vez podrá repercutir sobre el contratista, si procediese. Además, el artículo 176.3, b, de dicho Reglamento, extiende a la empresa contratista de las obras el deber de facilitar la actuación inspectora de la Administración, deber que habrá por ello de reflejarse asimismo en el contrato de ejecución de las obras entre dicha empresa y la Junta de Compensación.

\section{Recepción de las obras de urbanización}

Una vez concluida la ejecución de las obras de urbanización, la Administración actuante ha de verificar como es lógico el estado de las mismas, recibiéndolas en el caso de que se hayan realizado conforme al proyecto y se hallen en buen estado. La recepción es, pues, el acto por el que el contratista de las obras, una vez terminadas éstas, hace su entrega a la Administración municipal, que en tal caso viene obligada a aceptarlas, para destinarlas a los correspondientes fines, usos o servicios públicos.

La recepción de las obras ha de ser expresa, aunque la LOUA también admite que la recepción se produzca de manera tácita o de facto. Normalmente, la recepción tiene por objeto la totalidad de las obras de urbanización, aunque la Ley también admite la posibilidad de su recepción parcial, en el supuesto de que las obras -dice- sean susceptibles de ser ejecutadas por fases que puedan ser entregadas al uso público según lo establecido en el correspondiente instrumento de planeamiento, conforme al artículo 154.7.

La recepción de las obras comprende varias actuaciones procedimentales, que según la regulación establecida en el artículo 154 de la LOUA, son fundamentalmente las siguientes:

\footnotetext{
${ }^{32}$ Artículo 87 LOUA.
} 
Primera. La solicitud que ha de dirigir a la Administración municipal la persona o entidad que sea responsable de la urbanización según el sistema de actuación aplicado -sea contratista, concesionario, o agente urbanizador-, y cuya solicitud ha de ir acompañada de certificación final de las obras emitida por el técnico director de éstas o por técnico legalmente competente para ello. Esto será lo normal, aunque la Ley también faculta a la Administración para iniciar el procedimiento de oficio, sin perjuicio como es lógico de que en este caso haya de dar intervención a los interesados en las actuaciones.

Segunda. Dentro de los cuatro meses siguientes a la fecha de presentación de la solicitud ${ }^{33}$, ha de procederse a realizar el acto de recepción propiamente dicho, que incluye la comprobación o verificación técnica y material de las obras, a fin de determinar su estado y conformidad con el proyecto y condiciones de ejecución. Esta comprobación in situ ha de hacerse de forma contradictoria, con intervención por tanto no sólo del facultativo municipal sino también del técnico director de las obras y del facultativo de la persona o entidad responsable de la ejecución según el sistema de actuación, si es que en cuanto a este último así lo considere oportuno aquella persona o entidad. En dicho acto también han de estar presentes el alcalde o su delegado, en representación del municipio ${ }^{34}$. La presencia en este acto del presidente o representante de la Junta de Compensación, en el caso de que la ejecución se hubiere realizado por este sistema de actuación privada, parece evitar la doble recepción -primero por la Junta y después entrega por ésta al municipio- que el citado Reglamento de Gestión Urbanística estatal parece suponer en su artículo 180 (al fijar en tres meses, desde la recepción definitiva por la Junta, el plazo para su cesión posterior a la Administración municipal).

En el supuesto de que, como resultado de la verificación o comprobación administrativa, se concluyere que las obras están "en buen estado y con arreglo a los proyectos y prescripciones previstas", establece la Ley autonómica que "se darán por recibidas" ${ }^{55}$; pero en caso contrario, de observarse que las obras tienen defectos, no tendrá lugar su recepción, que se demoraría por ello hasta que sean corregidas las deficiencias dentro del plazo que a este efecto se fije, conforme al apartado 3 del artículo 154.

\footnotetext{
${ }^{33}$ Que puede ampliarse dos meses más, en total, pues, como máximo seis, en caso de prórroga, que ha de ser acordada por el municipio y de forma motivada, conforme a lo que prevé la LOUA, en su artículo 154.5.

34 Vid. el artículo 154.2 LOUA.

${ }^{35}$ Art. 154.2, pfo. 2 LOUA.
} 
La actuación, en todo caso, ha de formalizarse documentalmente, en un acta de recepción, en la cual, además de las personas intervinientes, ha de especificarse respecto a su objeto la fecha de terminación de las obras, el estado de las mismas y su conformidad al proyecto, atendiendo a lo cual:

-si las obras cumplieren estas condiciones, se declararán recibidas por la Administración municipal, que se hará cargo a partir de este momento de su conservación, a no ser que ésta corresponda a los propietarios agrupados legalmente en entidad urbanística de conservación, según se verá más adelante.

-pero si las obras fueren defectuosas, se harán constar en el acta los defectos observados, así como las medidas que sean precisas para remediarlos y el plazo máximo en que estas medidas hayan de ser ejecutadas ${ }^{36}$.

Tercera. En el caso de que las obras se hubieren recibido, comenzará el plazo de garantía, que la LOUA establece en un año. Durante este plazo, las obras han de destinarse al uso o servicio público, o de interés general, correspondiente. La conservación por el municipio o, en su caso, por la entidad urbanística de conservación, no es óbice al deber que "la persona o entidad que hubiera entregado las obras al municipio", esto es, el contratista en caso de gestión directa, concesionario, agente urbanizador o entidad de compensación, tiene de subsanar "los defectos o vicios de construcción apreciados"; a cuyo efecto el municipio ostenta la potestad correlativa para ordenar su subsanación, incluso de forma forzosa, en caso de incumplimiento, con cargo a la garantía prestada para asegurar la correcta ejecución de las obras.

En líneas generales, este régimen legal viene a seguir el que establece la legislación general de contratación administrativa para la recepción de las obras públicas ${ }^{37}$, cuya vigente regulación ha simplificado como es sabido el que establecía la Ley de Contratos de 1965 (recepción provisional, plazo de garantía y recepción definitiva), y que la actual Ley de Contratos ha refundido en un solo acto formal de recepción, seguido del plazo de garantía. (Algu-

\footnotetext{
${ }^{36}$ Respecto al buen o mal estado de las obras en el momento de producirse el acto de recepción, dado que la Administración viene obligada a recibir las obras conforme a las actuaciones y plazos legalmente establecidos, en el momento de producirse el acto de recepción no puede servir de excusa el mayor o menor tiempo que haya transcurrido entre la ejecución y la cesión. Vid. G. CORTÉS: La ejecución y recepción de las obras en las urbanizaciones de iniciativa particular, Edit. Aranzadi, 2001, pág. 273 y s., con cita de jurisprudencia.

37 Artículo 147 TRLCAP.
} 
nas leyes urbanísticas autonómicas, como la Ley 1/2001 de la Región de Murcia, en su artículo 163, han seguido no obstante el viejo esquema legal de recepción de las obras que la Ley de Contratos de 1965 establecía).

Cuarta. Por último, la Administración municipal ha de remitir al Registro de la Propiedad certificación administrativa del acta de recepción, a los efectos procedentes conforme a la legislación aplicable, establece el artículo 154.6 de la LOUA.

Esta Ley regula asimismo, como se ha indicado, el supuesto de recepción tácita de las obras de urbanización para el caso de que transcurriere el plazo máximo establecido para recibirlas formal y expresamente, sin que la recepción haya tenido lugar de este modo. La recepción tácita de las obras se entiende producida "por ministerio de la ley", produciendo asimismo el efecto de que el solicitante queda relevado del deber de su conservación, comenzando el cómputo del plazo de un año de garantía a partir de dicho momento ${ }^{38}$. La recepción se entiende producida, pues, legalmente de manera automática, por efecto del paso del tiempo desde la solicitud de recepción de las obras, sin que esta recepción tenga lugar mediante acto formal expreso; por lo que parece que no hay necesidad de deducirla ni aplicar la doctrina de los llamados hechos concluyentes, esto es, que manifiestaren inequívocamente la voluntad administrativa de recibir las obras -que por ejemplo se destinen de hecho al uso o servicio público, o que hayan sido inauguradas oficialmente, etc- que la jurisprudencia había sentado en análogos supuestos en materia de contratación administrativa.

El hecho de que la recepción tácita opere de forma automática según la LOUA, por el mero transcurso del tiempo, con independencia del estado real de las obras de urbanización, ni que decir tiene que indirectamente refuerza el papel que ha de tener y que cumple efectiva y materialmente el acto de recepción expresa, para poder acreditar lo que en definitiva importa y que no es otra cosa que el buen o el mal estado de las obras y evitar, en definitiva, con ello, que en este último caso la recepción llegue a tener lugar.

\section{CONSERVACIÓN DE LAS OBRAS DE URBANIZACIÓN}

Delimitar el ámbito del deber de conservación a que se refiere y regula la Ley andaluza $7 / 2002$, en su artículo 153 , obliga a definir ante todo su conte-

${ }^{38}$ Artículo 154.5, in fine, LOUA; cuyo precepto proviene del artículo 147.5, TRLCAP, que reproduce aquél, con la diferencia de referirse al instrumento de planeamiento, en lugar de al contrato. 
nido y alcance. Es indudable que se refiere a la "conservación de las obras de urbanización", que incluye según el precepto legal "el mantenimiento de las dotaciones y los servicios públicos correspondientes", según determina en su primer apartado dicho artículo. La tradicional problemática que en nuestra doctrina ha planteado el tema de la conservación de las urbanizaciones y en especial de las de iniciativa particular, desde la reforma sobre todo de la Ley del Suelo estatal de 1975-1976 ${ }^{39}$, no parece necesario reproducirla aquí, al menos en su globalidad. Ahora bien, supuesto que aquí nos referimos al deber de conservación de las obras de urbanización a partir del momento en que éstas hayan sido recibidas por la Administración, en un ámbito determinado, donde se hayan realizado legalmente mediante alguno de los sistemas de actuación ${ }^{40}$, el alcance del deber de conservación plantea ahora el problema de si cabe entender incluida en dicho deber la prestación de servicios públicos, dada la expresión legal "mantenimiento de... los servicios públicos" que el citado precepto legal autonómico utiliza para delimitar el ámbito objetivo de la conservación de las obras de urbanización.

Una respuesta positiva a esta cuestión parece que desbordaría el ámbito del deber de conservación, por varias razones. La primera, porque la función de mantenimiento -entiendo- ha de referirse a los bienes destinados o afectados a los servicios, esto es a las obras e instalaciones ejecutadas y recibidas por la Administración y que constituyen las vías públicas, incluido el subsuelo, las zonas verdes y demás espacios públicos, pero no la prestación de servicios públicos como los de alumbrado público, limpieza viaria y recogida de basuras, como no sea que, por determinadas circunstancias, como pudiera ser la lejanía de la urbanización que hiciera excesivamente costosa su prestación, ésta fuese asumida voluntariamente por los propietarios afectados en virtud de compromisos asumidos respecto a la Administración municipal. De no ser así, y ésta es la segunda razón para entender no incluidos en principio estos y otros servicios públicos, es que se produciría una desigualdad de trato entre los propietarios de suelo de una urbanización cuyas dotaciones públicas ha recibido la Administración y los demás administrados y vecinos del propio municipio;

\footnotetext{
${ }^{39}$ En la doctrina reciente, G. CORTÉS: La ejecución y recepción de las obras en las urbanizaciones de iniciativa particular, Edit. Aranzadi, 2001, esp. pág. 165 y sgs.

${ }^{40}$ La LOUA dice, en su artículo 153.2, "a través de alguno de los sistemas de actuación”: Lo normal será que la actuación, a este respecto, se haya realizado mediante el sistema de compensación -que implica de suyo la gestión privada-, aunque no haya que excluir de la temática que se expone el sistema de cooperación e incluso el de expropiación, cuando la gestión de la actividad pública urbanizadora se efectúe de forma indirecta, esto es, por concesión o agente urbanizador.
} 
máxime si se tiene en cuenta que servicios como los indicados de alumbrado público, limpieza viaria y recogida de basuras son servicios que la normativa básica de régimen local atribuye a todos los municipios como servicios mínimos obligatorios, y que además, respecto a los dos primeros, la Administración Local no puede exigir tasas ${ }^{41}$.

Otra cosa diferente es que entre en el deber de conservación a cargo de los propietarios, el mantenimiento de los espacios comunes de la urbanización que no sean de titularidad pública sino privada de la comunidad de propietarios y que hayan de gestionarse y costearse en régimen de propiedad horizontal conforme a la ley 8/1999, de 6 de abril, a que después se hace referencia. Y por supuesto, el caso de las urbanizaciones ilegales, cuya respuesta administrativa ha de darse en el terreno de la policía urbanística preventiva y de la protección de la legalidad y régimen sancionador, para evitar y en su caso restablecer la propia legalidad vulnerada e incluso la realidad física indebidamente alterada, lo que nos sitúa indudablemente en otro terreno, el de la patología y la indisciplina urbanística muy diferente del que aquí se trata.

Delimitado así el tema a considerar, veamos a quién corresponde el deber de conservación de las obras de urbanización, una vez recibidas éstas -expresa o tácitamente-por la Administración y que la Ley andaluza 7/2002 regula en su artículo 153.

\section{Atribución legal al municipio del deber de conservación}

Según este precepto legal, una vez recibidas las obras por la Administración municipal, ha de ser ésta la que a partir de ese momento asuma el deber de su conservación o mantenimiento. Reitera así esta Ley (artículo 153.2) el principio que ya estableciera la precedente legislación urbanística estatal, en el Reglamento de Gestión Urbanística de 1978, en su artículo 68.1, y que asimismo se infiere y resulta, como regla, de la propia titularidad del municipio que legalmente ostenta sobre dichas obras y las dotaciones correspondientes en cuanto públicas.

${ }^{41}$ Artículo 26.1, a, de la Ley 7/1985, de 2 de abril, y 21 de la Ley 39/1988, de 28 de diciembre. En especial, respecto al servicio de recogida de basuras, el artículo 55.2 del Reglamento (estatal) de Planeamiento Urbanístico de 23 de junio de 1978, al referirse a la evaluación económica, en el Plan Parcial, de la implantación de los servicios hace alusión a la recogida de basuras, "si procede". De ello hay que deducir que si el municipio cuenta con una infraestructura suficiente, aún en el supuesto de urbanizaciones no entregadas, no habrá inconveniente para que el servicio sea prestado por el Ayuntamiento, abonando los interesados la tasa correspondiente; pero si, por contra, no lo fuera, el propio plan debería prever un servicio propio asumiendo todos los costos del mismo (G. CORTÉS, cit. en la nota 39, pág. 194 y s.). 


\section{Conservación a cargo de los propietarios agrupados en una entidad urba- nística de conservación}

Especial atención requiere el supuesto de conservación de la urbanización por los propietarios de terrenos urbanizados en un determinado ámbito espacial, supuesto que ya venía previsto en el citado Reglamento estatal de Gestión Urbanística, en su artículo 68.2 y 3, cuando el deber de conservación viniera impuesto por el planeamiento urbanístico o por disposición legal. Además, en la doctrina que se ha ocupado del tema a propósito sobre todo de las llamadas urbanizaciones privadas o, como con mayor propiedad decía la Ley del Suelo estatal de 1975-1976, "urbanizaciones de iniciativa particular", se ha resaltado el que esta normativa se refiriera a los posibles compromisos entre el urbanizador y el Ayuntamiento sobre la futura conservación de las obras de urbanización y las garantías necesarias, como título jurídico legitimador de dicho deber ${ }^{42}$.

Con estos precedentes y por vía de salvedad a la regla que atribuye al municipio el deber de atender a la conservación de la urbanización, la Ley andaluza 7/2002 reitera también la posibilidad de que sean los propietarios agrupados en una entidad urbanística ad hoc quienes asuman el deber de hacerlo. El artículo 153.1 de la LOUA fija los requisitos a que se condiciona la aplicación del supuesto: que este deber sea asumido por los propietarios bien voluntariamente en virtud de compromisos asumidos -lo que normalmente puede darse en urbanizaciones de iniciativa particular ejecutadas por el sistema de compensación-, o bien por disposición del planeamiento urbanístico; y que, además, aquéllos se agrupen en una entidad urbanística de conservación. Aunque la Ley no lo establece de forma explícita, parece que cuando el deber de conservación resulte no de un compromiso libremente asumido sino de su imposición por el planeamiento, la disposición de éste ha de venir motivada en razón de tratarse de una carga o gravamen limitativo de derechos de particulares, impuesta por la Administración en ejercicio de su potestad de planeamiento, pero en atención de determinadas circunstancias que efectivamente concurran y que lo justifiquen fácticamente, como causa de su establecimiento.

\footnotetext{
${ }^{42} \mathrm{Al}$ tema he dedicado alguna atención en mi estudio "Costes y cuotas de urbanización y de conservación”, en Rev. de Derecho Urbanístico no 67 (1980), pág. 103 y sgs. Asimismo, G. FERNÁNDEZ FARRERES, "Las urbanizaciones de iniciativa particular: Introducción a su problemática jurídica”, Cívitas-REDA no 53, 1987. J. RUIZ RICO: Las urbanizaciones privadas, Edit. Montecorvo, 1987. E. SÁNCHEZ GOYANES: "El interés general y las urbanizaciones de iniciativa particular”, Rev. de Derecho Urbanístico no 150 (1996), pág. 59 y sgs.
} 
En razón de su objeto -la conservación de bienes públicos-, la comunidad de propietarios se constituye a este fin con la veste de entidad pública. Las entidades urbanísticas de conservación, determina la LOUA en su artículo 153.4, son entidades de derecho público, de adscripción obligatoria y personalidad y capacidad jurídicas propias para el cumplimiento de sus fines, desde su inscripción en el Registro de Entidades Urbanísticas Colaboradoras, aunque en su actuación vienen sujetas a la tutela de la Administración municipal ${ }^{43}$.

La participación de los propietarios en los costes de conservación, cuando éstos corran a su cargo, habrá de determinarse atendiendo: en primer lugar, a lo que dispongan los estatutos de la entidad de conservación o, en su defecto, atendiendo a la participación que a los propietarios les corresponda en el sistema de actuación de la unidad de ejecución (proyecto de equidistribución o reparcelación); aunque en último término y para el caso de que se haya constituido en régimen de comunidad civil conforme a la Ley de Propiedad Horizontal, la fijación de las cuotas de conservación se efectuará conforme a la normativa de esta Ley, que en la actualidad, según la reforma establecida por la Ley 8/1999, de 6 de abril, se refiere en su artículo 24 a la realidad de los llamados complejos inmobiliarios privados, que incluyen no sólo los edificios de viviendas y locales sino también sus zonas y servicios comunes, zonas ajardinadas, deportivas, etc ${ }^{44}$. Queda pues, en definitiva y en todo caso, a la voluntad de los propietarios, expresada en el correspondiente instrumento jurídico, sean los estatutos de la entidad urbanística de conservación, o de la entidad que hubiere llevado a cabo la urbanización en otro caso, o sea en los estatutos de la comunidad de propietarios, en donde se recoja el ejercicio del poder dispositivo de aquéllos, el modo de distribuir entre los mismos la carga que supone conservar o mantener la urbanización.

\footnotetext{
${ }^{43}$ Sobre este tipo de entidades públicas de base asociativa privada, remito a las consideraciones hechas con base en la más autorizada doctrina (GARCÍA DE ENTERRÍA, FERNÁNDEZ RODRÍGUEZ, PAREJO ALFONSO), en el estudio publicado en la Rev. de Derecho Urbanístico no 67 cit., en la nota precedente, pág. 106 y sgs. Asimismo, E. SÁNCHEZ GOYANES, cit. en la nota anterior, pág 78 y sgs.; y E. CORRAL GARCÍA: Las entidades de conservación, en la Rev. Práctica Urbanística, $\mathrm{n}^{\mathrm{o}} 16$ (2003), pág. 14 y sgs.

${ }^{44}$ J. ESTRUCH y R. VERDERA: Urbanizaciones y otros complejos inmobiliarios en la Ley de Propiedad Horizontal, Edit. Aranzadi, 2000. E. PÉREZ PÉREZ: La propiedad inmobiliaria, sus formas y su inscripción registral, Edit. Bosch, 2001, con específico tratamiento, en su capítulo XIV, de los complejos inmobiliarios privados (pág. 745 y sgs.); asimismo "Informe jurídico emitido a solicitud de la entidad urbanística de conservación X" (inédito; pendiente de publicación en la Revista de Derecho Urbanístico y Medio Ambiente).
} 
La LOUA no establece, sin embargo, límite temporal alguno del deber de conservación de las obras de urbanización cuando ésta recaiga en los propietarios. Parece que habrá que estar a este respecto a lo que se haya determinado en el planeamiento urbanístico, cuando sea éste el que impone el deber de conservación en razón de determinadas circunstancias fácticas y jurídicas, y a los compromisos asumidos en su caso por los propietarios respecto de la Administración municipal, de acuerdo o en defecto de previsión de aquél. La jurisprudencia recaída a este respecto sobre la normativa urbanística estatal precedente, antes citada -cuya normativa tampoco fijaba límite temporal al deber-, admitía la posibilidad de que el plan urbanístico impusiera a los promotores y a los futuros propietarios de la urbanización el deber de conservarla sin límite de tiempo, indefinidamente ${ }^{45}$; no obstante lo cual ha terminado abriéndose paso el criterio de que el deber de conservación de la urbanización no puede imponerse de modo indefinido, sino venir sujeto a un determinado plazo ${ }^{46}$, en razón sobre todo de la titularidad pública de los bienes -calles, zonas verdes y demás dotaciones públicas- de la urbanización. No cabe desconocer tampoco que este último criterio viene fundamentado en el precedente Reglamento de Planeamiento Urbanístico estatal de 1978, que establece respecto a la conservación de urbanizaciones de iniciativa particular, que en el caso de que haya de conservarse a cargo de los propietarios ha de indicarse el "período de tiempo al que se extenderá la obligación de conservación”, y cuyo precepto reglamentario sigue siendo aplicable, aunque sea de modo transitorio, en el ámbito de la Comunidad Autónoma andaluza conforme establece su propia Ley $7 / 2002^{47}$.

\section{La conservación de las urbanizaciones preexistentes en el régimen transito- rio de la Ley andaluza}

La nueva regulación que establece la LOUA, en sus artículos 153 y 154, no es sin embargo aplicable de modo inmediato, ni siquiera a la entrada en vigor de la Ley sino cuando se realice la adaptación a ella, en cada municipio,

\footnotetext{
45 Sentencia del Tribunal Supremo de 14 de marzo de 1989 (Arz. 2079), que reitera a otra s. de 12 de abril de 1985 (Arz. 2205), que hacía referencia a "las especiales circunstancias del fenómeno urbanístico moderno, productor en ocasiones de eclosiones en la que las demandas de servicios están muy por encima de las posibilidades de la respectiva Administración".

${ }^{46}$ Así, la sentencia del TS de 29 de noviembre de 1993 (Arz. 8796) y otras que cita G. CORTÉS, ob. cit. en la nota 39 , pág. 186.

${ }^{47}$ Disp. Transitoria 9 ${ }^{\mathrm{a}}$, a).
} 
de su planeamiento urbanístico general. Así lo establece la Disposición Transitoria Sexta de la propia Ley autonómica, según la cual "las obras y los servicios de urbanización cuya conservación se encuentre encomendada a la entrada en vigor de esta Ley a entidades urbanísticas con tal finalidad u objeto, continuarán siendo conservadas con arreglo al mismo régimen sin que les sea de aplicación lo dispuesto en los artículos 153 y 154 mientras no se produzca la plena adecuación del planeamiento general del municipio correspondiente a esta Ley".

La legislación urbanística precedente aplicable en Andalucía no era otra que la contenida en el Reglamento estatal de Gestión Urbanística de 1978, sobre entidades de conservación (artículos 24.2, c y 3; 25.2 y 3; y 26 a 30) y sobre la propia conservación de la urbanización (arts. 67 a 70), que normalmente presuponía la existencia y ejecución de un plan de iniciativa particular (artículo 104.1 y 2 de la Ley del Suelo estatal de 1992, asumido como régimen autonómico propio por la Ley andaluza 1/1997, de 18 de junio, en su artículo único), con el complemento del Reglamento de Planeamiento Urbanístico, asimismo de 1978, que facultaba a la Administración para imponer en el acto de aprobación provisional y definitiva, "las condiciones, modalidades y plazos que fueran conveniente", y que podían fijar incluso previsiones sobre la futura conservación de la urbanización, con los compromisos y garantías de su cumplimiento.

Parece innecesario volver aquí sobre la precedente normativa, a la que la más autorizada doctrina ha dedicado la necesaria atención ${ }^{48}$, como no sea para concluir en la proyección ulterior de su régimen, por lo que respecta a las entidades urbanísticas de conservación constituidas conforme a aquélla, y cuya conservación tuviesen encomendada a la entrada en vigor de la LOUA, en cuyo caso la aplicación del nuevo régimen que esta Ley establece -y al que nos hemos referido en los epígrafes precedentes-, se condiciona ope legis a que el municipio correspondiente cuente con planeamiento urbanístico general adaptado -con "plena adecuación", dice- a la propia LOUA; no siéndole de aplicación entretanto por ello las disposiciones de sus artículos 153 y $154^{49}$.

\footnotetext{
${ }^{48}$ A destacar, por su tratamiento monográfico del tema, la obra de G. CORTÉS CORTÉS citada en la nota 39, in totum; asimismo, el estudio de E. SÁNCHEZ GOYANES citado en la nota 42.

${ }^{49}$ No es óbice ello a que, cuando se apliquen estos artículos, conforme a la Disp. Transitoria Sexta de la propia LOUA, continúen aplicándose asimismo, pero como Derecho supletorio, aquellos preceptos de los citados Reglamentos estatales, de Planeamiento y de Gestión Urbanística, que sean compatibles con la nueva regulación de aquélla, de conformidad con su Disposición Transitoria Novena.
} 